\title{
Average stride length and stride rate of Thoroughbreds and Quarter Horses
}

\section{during 'Sprint' and 'Classic' races}

1 Fernando B. Vergara-Hernandez*1, Brian D. Nielsen ${ }^{1}$, Cara I. Robison ${ }^{1}$, Taylor A. Fabus ${ }^{1}$, Jasmin L.

2 Kompare $^{1}$, Rebecca A. LeCompte Lasic ${ }^{1}$, and Aimee C. Colbath ${ }^{2}$

$3{ }^{1}$ Department of Animal Science, Michigan State University, East Lansing, Michigan, United States

$4 \quad{ }^{2}$ Department of Large Animal Clinical Sciences, Michigan State University, East Lansing, Michigan,

$5 \quad$ United States

$6 *$ Corresponding author

$7 \quad$ E-mail: vergarah@msu.edu (FBV)

8 Abstract

The main factors influencing speed in athletes are stride length (SL) and stride rate (SR).

10 However, conflict remains whether SL or SR is the key determinant of higher speeds. Quarter Horses

$11(\mathrm{QH})$ generally reach higher speeds in their races than do Thoroughbreds (TB). However, the influence

12 of SL and SR on this greater speed is unclear. Therefore, the main objective of this study was to

13 compare SL and SR in QH and TB raced in short (sprint) and long (classic) distances. We hypothesized

14 that $\mathrm{QH}$ have a higher SR in comparison to TB, and SR decreases as distance increases. Two race

15 distances were analyzed for each breed: QH races of 100.6 and $402.3 \mathrm{~m}$, and TB races of 1,207.0 m

16 and 2,011.7 m. Data from twenty horses were obtained, consisting of five horses from each race

17 distance (10 QH and $10 \mathrm{~TB})$. Five individuals watched recordings of each race three times counting

18 the number of strides taken by each winning horse. The SR was calculated using the average number

19 of strides over a given race duration, and SL was determined by calculating the total number of strides 
over the distance covered. Speed was calculated dividing the distance by the time of the winning horse.

21 The PROC Mixed Procedure was used to identify statistical differences between breeds, and between

22 distances within the same breed. Results showed that although the SL of the TB was longer in

23 comparison with the $\mathrm{QH}(\mathrm{P}<0.001)$, the average $\mathrm{SR}$ in $\mathrm{QH}$ was higher than in $\mathrm{TB}(2.88$ vs $2.34+0.03$

24 strides $/ \mathrm{s} ; \mathrm{P}<0.001)$. Further, $\mathrm{QH}$ classic distance demonstrated a faster speed than $\mathrm{TB}$ at either distance

$25(\mathrm{P}<0.001)$. In conclusion, $\mathrm{QH}$ achieve a higher $\mathrm{SR}$ in comparison to TB (between 14-20\% more than

26 TB), confirming the importance of SR in achieving high racing speeds.

\section{Introduction}

Whether it is a human sprinter, a marathoner, or a racehorse, speed is critical to performance. It is a common belief among sports enthusiasts that a greater stride length (SL) will result in a faster individual. While many have been focusing only on SL, velocity is dictated by SL and SR [1]. Daniels

31 [2] identified that elite human athletes maximize their performance by reaching an average step rate of

$32180 \mathrm{steps} / \mathrm{min}$ (90 strides/min) or more in racing distances of $800 \mathrm{~m}$ or more. Some believe that SL and

33 SR may have an inverse relationship [3]. In horses, it is currently unknown whether SL or SR is most

34 influential in racing speed. Determining the importance of SL or SR on racing speed could have far

35 reaching implications on horse selection.

Similarly, horse enthusiasts often believe that SL is the most important factor influencing speed.

37 For instance, the outstanding racehorses Man O' War, Secretariat, and Justify have SL reported to be

misconception that speed in horses is most strongly influenced by SL. Thoroughbreds (TB) are the world's most widely distributed racehorse and are well-known for their speed [5]. Triple crown winners

41 have achieved peak speeds of $61.2 \mathrm{~km} / \mathrm{h}$ [6]. However, this is not the fastest horse breed. Quarter 42 Horses $(\mathrm{QH})$, developed in the United States, are the fastest horse to run a quarter of a mile (403.3 m) 
43 [7], reaching top speeds of 87.5 to $92.6 \mathrm{~km} / \mathrm{h}[7,8]$. QH and TB typically race different distances. For

44 instance, QH most often run distances between 91-796 m, and TB usually run between 1,006-3,219 m

45 (5-16 furlongs) [9].

Previous studies investigating the effect of SL and SR on racing speed have conflicting results.

An early study showed that SL was responsible for the increase in speed, up to $8.3 \mathrm{~m} / \mathrm{s}$ [10]. However,

at higher speeds $(11.7 \mathrm{~m} / \mathrm{s})$, increasing SR resulted in faster speeds [10]. Another study using three TB

at six different speeds reported that, as the speed increases, both SL and SR increased nearly linearly.

Yet, the fastest TB from the study had the shortest SL and highest SR at maximum speed indicating

that, at higher speeds, SL may decrease as SR increases [11]. In another study using nine TB, it was

observed that the SR increased linearly without signs of a plateau [12].

The objective of the current study was two-fold. The first objective was to evaluate the average

SL and SR in both QH and TB breeds within their breed-specific races. The second objective was to

determine if SL and SR are influenced by the distance raced. Therefore, it was hypothesized that QH

have a greater average SR than TB, and that SR will decrease as running distance increases. Finally, it

was hypothesized that SL would decrease as the SR increases.

\section{Material and Methods}

To examine differences between breeds and between short and long race distances, "sprint" races

63 at Los Alamitos Race Course (www.losalamitos.com). For the TB races, the Breeders' Cup Sprint,

64 1,207.0 m (6 furlongs), and Breeders' Cup Classic, 2,011.7 m (10 furlongs), were analyzed. The 
65 Breeders' Cup races were held at Santa Anita Park (www.santaanita.com) in 2008, 2009, and 2012,

66 and at Churchill Downs (www.churchilldowns.com) in 2010 and 2011 [13]. This resulted in a total of

6720 horses being analyzed (5 QH sprint, 5 QH classic, 5 TB sprint, 5 TB classic). Five individuals

68 watched recordings of each race three times (in slow motion when necessary) and counted the strides

69 of the winning horse. If, during periods of a race, the winning horse was not in camera view, the horse

70 in the lead was chosen as a surrogate horse for which to count strides until the winning horse was back

71 in the camera view. From the 15 viewings of each race (five individuals viewed each race three times),

72 the average number of strides for the winning horse was calculated.

For the QH races, the stride count began when the starting gates opened, signifying the official

start to the race. For TB races, the stride count began after the horses left the starting gates, had

completed the "run-up" (passed the 'flagman' or 'tripped the beam'), and the race officially started.

The average SL was determined by dividing the length of the race by the average number of strides

taken during the race. The SR was computed by dividing the number of strides by the race time in

seconds. Further, the average speed and standard error of each type of race was calculated using the

distance of each race and then divided by time for each winning horse.

82 between $\mathrm{QH}$ and TB, along with differences between distances within each breed. Differences were 83 considered significant at $\mathrm{P} \leq 0.05$.

\section{Results}


87 the breed, with the highest SR being $2.96 \pm 0.04$ strides/s during the $101-\mathrm{m} \mathrm{QH}$ race and the lowest SR

$88(2.23 \pm 0.04$ strides/sec) in the 2,011.7-m Breeders' Cup Classic (Table 1).

TABLE 1. Average stride rate (strides/sec) for Quarter Horses and Thoroughbreds.

\begin{tabular}{|c|c|c|c|c|c|}
\hline \multirow[b]{3}{*}{ Stride rate } & \multicolumn{4}{|c|}{ Breed } & \multirow[t]{2}{*}{ SEM } \\
\hline & \multicolumn{2}{|c|}{ Quarter Horse $(n=10)$} & \multicolumn{2}{|c|}{ Thoroughbred $(n=10)$} & \\
\hline & \multicolumn{2}{|c|}{$2.88^{\mathrm{a}}$} & \multicolumn{2}{|c|}{$2.34^{b}$} & 0.03 \\
\hline & \multicolumn{4}{|c|}{ Race length (meters) } & \\
\hline & $100.6(n=5)$ & $402.3(n=5)$ & $1,207.0(n=5)$ & $2,011.7(n=5)$ & \\
\hline Stride rate & $2.96^{\mathrm{a}}$ & $2.81^{\mathrm{b}}$ & $2.45^{\mathrm{c}}$ & $2.23^{d}$ & 0.04 \\
\hline
\end{tabular}

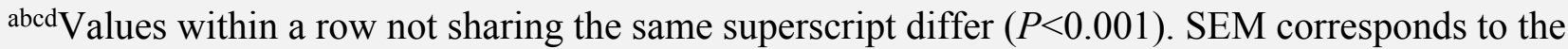
standard error of the mean.

Average values for SL are presented in Table 2. A greater SL was observed in TB compared to $\mathrm{QH}$ at all distances $(\mathrm{P}<0.001)$. Further, $\mathrm{QH}$ had the shortest $\mathrm{SL}$ in the 100.6- $\mathrm{m}$ race, with it increasing

91 in the 402.3-m race. TB stride length did not differ significantly between distances.

TABLE 2. Average stride length (meters) for Quarter Horses and Thoroughbreds.

\begin{tabular}{|c|c|c|c|c|c|}
\hline \multirow[b]{3}{*}{ Stride length } & \multicolumn{4}{|c|}{ Breed } & \multirow[t]{2}{*}{ SEM } \\
\hline & \multicolumn{2}{|c|}{ Quarter Horse $(n=10)$} & \multicolumn{2}{|c|}{ Thoroughbred $(n=10)$} & \\
\hline & \multicolumn{2}{|c|}{$5.9^{\mathrm{a}}$} & \multicolumn{2}{|c|}{$7.4^{\mathrm{b}}$} & 0.11 \\
\hline & \multicolumn{5}{|c|}{ Race length (meters) } \\
\hline & $100.6(n=5)$ & $402.3(n=5)$ & $1,207.0(n=5)$ & $2,011.7(n=5)$ & \\
\hline Stride length & $5.0^{\mathrm{a}}$ & $6.8^{\mathrm{b}}$ & $7.3^{\mathrm{c}}$ & $7.5^{\mathrm{c}}$ & 0.04 \\
\hline
\end{tabular}

The average speeds for each breed and each race are presented in Table 3. The average speed for

$93 \mathrm{QH}$ and $\mathrm{TB}$ did not differ when calculating the speed during the official races (which involves a

94 standing start for $\mathrm{QH}$ and a running start with $\mathrm{TB}$ ), although the average speed for each distance varied 
with $\mathrm{QH}$ racing the classic distance having the fastest average speed $(\mathrm{P}<0.001)$. On the other hand, TB showed a significantly faster speed in sprint versus classic distances $(\mathrm{P}<0.001)$.

TABLE 3. Average speed (m/s), time and SEM for Quarter Horses $(\mathrm{QH})$ and Thoroughbreds (TB) calculated from when the race officially started for each breed; from a standing start when the starting gates open for $\mathrm{QH}$ and from a running start when TB completed the "run-up".

Breed

$$
\text { Quarter Horse }(\mathbf{n}=\mathbf{1 0})
$$

Speed

16.87

\begin{tabular}{|c|c|c|c|c|c|}
\hline \multicolumn{6}{|c|}{ Race length (meters) } \\
\hline & $100.6(n=5)$ & $402.3(n=5)$ & $1,207.0(n=5)$ & $2,011.7(n=5)$ & \\
\hline Speed & $14.76^{\mathrm{a}}$ & $18.99^{\mathrm{b}}$ & $17.68^{\mathrm{c}}$ & $16.54^{\mathrm{d}}$ & 0.04 \\
\hline Time & $6.82^{a}$ & $21.19^{b}$ & $68.28^{\mathrm{c}}$ & $121.66^{d}$ & 0.20 \\
\hline
\end{tabular}

${ }^{\text {abcd }}$ Values within a row not sharing the same superscript statistically differ $(P<0.001)$. SEM corresponds to the standard error of the mean.

\section{Discussion} and SR decreases as race distance increases (Table 1). In terms of SL, the study data suggest QH have a shorter SL than TB. In addition, as hypothesized, the shortest races with the highest SR have the shortest average SL. Similarly, as also hypothesized, as the distance of the race increased, the SL also increased, but only up to the point at which the TB race distances were reached as no differences were seen between TB racing at the sprint or classic distances (Table 2).

Though it is recognized that $\mathrm{QH}$ are faster than $\mathrm{TB}[8,14]$, the results obtained from the calculations used in this study to determine average speed (distance divided by time) would appear to

106 lack support for this. Despite differences in speed at every race distance, the overall average speed by

107 both breeds were not different - thereby providing temptation to conclude that $\mathrm{QH}$ and $\mathrm{TB}$ race at 
108 similar speeds. Likewise, if one compares the world speed records at the same distance (402 m), they

109 appear somewhat similar. Currently, the QH record is held by 'First Moonflash', with 20.27 seconds

110 [15], and the TB record is held by 'Winning Brew', with 20.57 seconds [16]. In reality, while accurate,

111 calculating the speed using the time of the race and distance fails to take into consideration that $\mathrm{QH}$

112 races are timed from when the starting gates begin to open and the horse is standing still while TB

113 races are timed after horses have already started running [7] and have traversed the "run-up" which is

114 highly variable [17]. While TB tend to be relatively constant in their speed throughtout a race and the

115 peak speed reached often is somewhat similar to their average speed, this is not true for QH. The

116 average speed for a $\mathrm{QH}$ takes into account the period in which they are standing still and have not yet

117 begun running. Pratt [8] has estimated it can be $0.6 \mathrm{sec}$ before a $\mathrm{QH}$ has taken a step away from the

118 starting gates. Using that estimate, roughly $9 \%$ of the race time for the QH sprint races is spent on the

119 very first step away from the starting gate. While constituting only 3\% of the race time for the $\mathrm{QH}$

120 classic races, it still represents a period during the race when the speed of the horse is at or near $0 \mathrm{~m} / \mathrm{s}$.

121 Even after that, $\mathrm{QH}$ are accelerating during the initial portion of the race whereas TB had that period

122 of acceleration during the "run-up" before the official timing of the race began. Although QH racing

123 at the classic distance demonstrated the fasted speed, higher peak speeds could have been achieved

124 during the sprint races. However, peak speed measurements were not within the scope of this study.

125 While the general public tends to believe that a long stride is correlated strongly with greater

126 speed, this study indicates that performance is dependent on both SL and SR. That stated, a difference

127 in stride rate within breeds at different distances is noteworthy. At the classic distances for each breed,

128 the average $\mathrm{QH}$ speed over the entire race was $2.5 \mathrm{~m} / \mathrm{s}$ faster than the TB speed (even with the $\mathrm{QH}$

129 timed from a standing start). With QH racing at higher speeds than TB, it is clear that the SR plays a

130 greater role in reaching peak speeds in short distances. This findings go in agreement with the study

131 by Hay [18] that stated, at maximum speeds, the SL remained constant or decreased slightly, contrary 
132 to the SR that was increased with the increase in speed. In fact, the fastest horse analyzed showed the

133 highest SR but the lowest SL, showing the important role of both factors and not only SL. Moreover,

134 the findings of another study, showed that both variables (SR and SL) increased linearly, although SL

135 showed a tendency to decrease [11]. Of note, with the average SR being $2.96 \pm 0.04$ strides/s during

136 the sprint QH races, some of the horses had over 3 strides per second - a truly amazing physical feat.

137 In the case of human athletes, they reach maximum speeds and performance using different

138 strategies, Elite human sprinters have been shown to possess individual preference, whether it is a

139 higher SR or SL [3]. Yet, Hunter et al. [19] concluded that SR may be the most significant factor

140 influencing speed in short distances. They examined 28 human athletes performing repeated sprint

141 trials. Results indicate the best individual results were obtained when they had a higher SR. In fact, a

142 negative correlation was found between SR and SL $(r=-0.70)$. Acknowledging that there are distance

143 differences between and within the breeds, the differences in SR and SL average between breeds can

144 be an adjustment in racing strategy according to race distance. In other words, if trained and raced like

145 a $\mathrm{QH}$, a TB running for distances of $402 \mathrm{~m}$ or less may have a similar recorded time as a $\mathrm{QH}$ racing

146 the same distance. For example, QH are often not ridden every day, usually being galloped only a few

147 days per week at most [7]. This is in contrast with the TB training in which it is common practice to

148 gallop the horses on most days and for longer distances during each ride, developing more endurance

149 ability required for longer races in comparison with the typical distances in QH [9]. Interestingly, in

150 the study of Ferrari et al. [20], the SR was increased after six months of training mature TB.

151 The difference in muscle mass between QH and TB is also a likely factor in the speed difference.

152 It is reported that more than $75 \%$ of fiber muscles are Type-II in TB [21]. However, QH have a greater

153 proportion of muscle fibers II-X when compared to TB which, in combination with their increased

154 muscle mass compared to TB, may explain their increased speed [7, 22, 23]. Moreover, having this

155 larger II-X fiber proportion in QH could provide a higher muscle glycolytic power and a higher 
maximum speed when raced short distances. While differences in muscle fiber composition are likley

157 to be heavily influenced by genetics, differences in training techniques may also have an influence.

The current study had some limitations. In the QH races, the distance horses ran was likely very

similar to the official distance of the race as QH typically run in a straight line. In contrast, the TB

160 races were run on an oval. Often winning horses traveled greater distances than the official race

161 distance unless they happened to be on the rail for the entire race, thus decreasing the precision in the

162 calculation of the average SL. In truth, the average TB SL is likely slightly greater than what is reported

163 in this study due to that variation. This does not negate the breed differences in SL, but it is

164 acknowledged that the difference between breeds could be even greater.

Another limitation was the difficulty of counting the short steps of QH at the beginning of the

races. As mentioned previously, $\mathrm{QH}$ races begin as the starting gates open [14] and acceleration is

167 dramatic. There is a short period in a $\mathrm{QH}$ race when the horse is standing still and has not left the gate.

168 During that rapid acceleration, QH take several short strides [8]. However, by having 15 views of each

169 race, the challenge associated with counting those first few strides should have been ameliorated. By

170 contrast, TB races begin when the first horse crosses in front of the flagman or electronic beam - a

171 short distance in front of the starting gates [7]. While the TB races officially start while the horses are

172 already running and, hence, are taking full strides (an advantage to being able to count strides), there

173 is some degree of uncertainty in terms of being to determine exactly when the horse crossed that line.

174 With repeated viewing of each race by five individuals, this uncertainty was likely minimized and a

175 meter or so difference in starting point would have only a minor impact on the number of strides taken

176 over the longer distance of the TB races. This difference in the start and how it is timed (running versus

177 standing start) makes comparing SR and SL during different segments of the race challenging,

178 especially at the start of the race. It was determined that only average differences in SR and SL over

179 the entire race could be performed accurately, as opposed to, for instance, comparing SR and SL in the 
last $100 \mathrm{~m}$ of the race (which would represent the entire race for the $\mathrm{QH}$ sprint races). As a result of

181 these differences in the type of racing, comparing TB and QH over the same distance could lead to inaccurate conclusions. Therefore, it is also acknowledged that differences between breeds are confounded with distance.

Besides the novelty of reporting the amazingly high SR seen in racing QH (especially at the

185 shorter distance), this study illustrates other considerations as it relates to other physiological systems

186 within the racing QH. First, the study raises some potential questions regarding how an increasing SR

may affect the respiratory system. A locomotor-respiratory coupling system has been described in horses cantering and galloping [24, 25]. If this coupling system remains true at high speeds, the average respiratory rate may reach 134 to 147 breaths/min in the $\mathrm{TB}$ and 169 to 178 breaths/min in the QH with some QH individuals in the sprint races likely taking over 3 breaths/s. This respiratory rate is between 14-20\% higher in the QH than the 148 breaths/min previously reported for TB racehorses [25, 26].

Although clarifying the deeper mechanisms and effects on respiratory system are beyond the scope of this study, further studies are needed to determine the potential impact on this system due to the high SR, especially for QH.

Beyond the respiratory system, the average SR findings also have possible implications for the

196 dynamics of the equine lower limb and hoof. During each stride, the hoof momentarily comes to a halt

197 during the stance phase of the stride (other than minor rotations or sliding of the hoof on the ground).

198 For racing QH taking three strides per second, this suggests that three times during each second the 199 hoof experiences rapid deceleration as the hoof comes to a stop and then experiences rapid acceleration 200 as the hoof leaves the ground during the swing phase. For horses previously reported to reach speeds 201 of around $89 \mathrm{~km} / \mathrm{h}[8,14]$, it suggests that the hoof on these QH may have to reach double that speed 202 or greater (nearly $180 \mathrm{~km} / \mathrm{h}$ ) at some point in the swing phase. While not the point of this project, with 
enhanced technology being developed, it would be interesting to determine peak speeds the hooves of

racing $\mathrm{QH}$ achieve and determine the forces associated with such rapid acceleration and deceleration.

In conclusion, despite some limitations in methodology, differences between breeds and within

Therefore, the analysis of an equine athlete must consider both SR and SL as determinants of potential

affect the integrity of the respiratory system in animals with high SR, especially in the short QH races.

\section{Author Contributions}

211 Conceptualization: Brian D. Nielsen, Cara I. Robison.

212 Data curation: Cara I. Robison, Fernando B. Vergara-Hernandez

213 Formal analysis: Cara I. Robison, Fernando B. Vergara-Hernandez

214 Funding acquisition: Brian D. Nielsen, Aimee C. Colbath.

215 Investigation: Fernando B. Vergara-Hernandez, Brian D. Nielsen, Cara I. Robison, Taylor A. Fabus,

216 Jasmin L. Kompare, Rebecca A. LeCompte Lasic.

217 Methodology: Brian D. Nielsen, Cara I. Robison.

218 Project administration: Brian D. Nielsen, Aimee C. Colbath.

219 Resources: Brian D. Nielsen, Aimee C. Colbath

220 Software: Cara I. Robison, Fernando B. Vergara-Hernandez.

221 Supervision: Brian D. Nielsen, Aimee C. Colbath.

222 Validation: Brian D. Nielsen, Aimee C. Colbath, Cara I. Robison.

223 Visualization: Fernando B. Vergara-Hernandez, Brian D. Nielsen, Aimee C. Colbath.

224 Writing - original draft: Fernando B. Vergara-Hernandez, Brian D. Nielsen 
225 Writing - review \& editing: Fernando B. Vergara-Hernandez, Brian D. Nielsen, Aimee C. Colbath,

226 Cara I. Robison, Taylor A. Fabus, Jasmin L. Kompare, Rebecca A. LeCompte Lasic.

227 References

228 1. Clayton HM. Horse species symposium: Biomechanics of the exercising horse. Journal of animal

229 science. 2016;94(10):4076-86. doi:10.2527/jas2015-9990

230 2. Daniels J. Daniels’ Running Formula. Champaign, IL: Human Kinetics.

231 3. Salo AI, Bezodis IN, Batterham AM, Kerwin DG. Elite sprinting: are athletes individually step-

232 frequency or step-length reliant. Med Sci Sports Exerc. 2011;43(6):1055-62.

233 doi:10.1249/MSS.0b013e318201f6f8

234 4. von Hippel P. Why the one horse who ran faster than Justify in the Preakness was only third.

235 Thoroughbred racing commentary. 2019 May 17 [Cited 2021 March 16]. Available from:

236 https://www.thoroughbredracing.com/articles/why-one-horse-who-ran-faster-justify-preakness-only-

237 came-third/

238 5. Bower MA, McGivney BA, Campana MG, Gu J, Andersson LS, Barrett E, et al. The genetic

239 origin and history of speed in the Thoroughbred racehorse. Nature communications. 2012;3(1):1-8.

240 doi:10.1038/ncomms1644

241 6. Denny MW. Limits to running speed in dogs, horses and humans. Journal of Experimental

242 Biology. 2008;211(24):3836-49. doi:10.1242/jeb.052886

243 7. Nielsen BD. Training the racing Quarterhorse. In: Hodgson DR, McKeever KH, McGowan CM,

244 editors. The athletic horse: principles and practice of equine sport medicine. 2 nd ed. St. Louis:

245 Elsevier; 2014. pp. 354-360. 
246 8. Pratt GW. Clocking the fastest horses on earth. The Quarter Racing Journal. 1991;4:36-40.

247 9. Hodgson DR. Training the Thoroughbred Racehorse. In: Hodgson DR, McKeever KH, McGowan

248 CM, editors. The athletic horse: principles and practice of equine sport medicine. 2nd ed. St. Louis:

249 Elsevier; 2014. pp. 302-304.

250 10. Dušek J, Ehrlein HJ, Engelhardt WV, Hörnicke H. Beziehungen zwischen Trittlänge,

251 Trittfrequenz und Geschwindigkeit bei Pferden 1. Zeitschrift für Tierzüchtung und

252 Züchtungsbiologie. 1970;87(1-4):177-88. doi:10.1111/j.1439-0388.1970.tb01333.x

253 11. Yamanobe A, Hiraga A, Kubo K. Relationships between stride frequency, stride length, step

254 length and velocity with asymmetric gaits in the Thoroughbred horse. Japanese Journal of Equine

255 Science. 1993;3(2):143-8. doi:10.1294/jes1990.3.143

256 12. Witte TH, Hirst CV, Wilson AM. Effect of speed on stride parameters in racehorses at gallop in

257 field conditions. Journal of Experimental Biology. 2006;209(21):4389-97. doi:10.1242/jeb.02518

258 13. Breeders' Cup. Races. 2020 [Cited 2021 March 16] available from:

259 https://www.breederscup.com/races

260 14. Nielsen BD, Turner KK, Ventura BA, Woodward AD, O'Connor CI. Racing speeds of quarter

261 horses, thoroughbreds and Arabians. Equine Veterinary Journal. 2006;38(S36):128-32.

262 doi:10.1111/j.2042-3306.2006.tb05528.x

263 15. Equibase. 2020a. Sunland Park Track Records. [Cited 2021 March 17] available from:

264 https://www.equibase.com/premium/eqbTrackRecords.cfm?trk=SUN\&cy=USA

265 16. Equibase. 2020b. Sunland Park Track Records. [Cited 2021 March 17] available from:

266 http://www.equibase.com/premium/eqbTrackRecords.cfm?trk=PEN\&cy=USA 
17. Thoroughbred Idea Foundation. Run-ups cause inaccuracies that are 'an affront to integrity'.

2020 Nov 11 [Cited 2021 May 13] available from: https://www.paulickreport.com/horseplayers-

category/thoroughbred-idea-foundation-run-ups-cause-inaccuracies-that-are-an-affront-to-integrity/

270

18. Hay JG. Cycle rate, length, and speed of progression in human locomotion. Journal of applied

Biomechanics. 2002;18(3):257-70. doi:10.1123/jab.18.3.257

272

19. Hunter JP, Marshall RN, McNair PJ. Interaction of step length and step rate during sprint

running. Medicine \& Science in Sports \& Exercise. 2004;36(2):261-71.

274

doi:10.1249/01.MSS.0000113664.15777.53

20. Ferrari M, Pfau T, Wilson AM, Weller R. The effect of training on stride parameters in a cohort of National Hunt racing Thoroughbreds: A preliminary study. Equine veterinary journal.

2009;41(5):493-7. doi:10.2746/042516409X374591

21. Kawai M, Minami Y, Sayama Y, Kuwano A, Hiraga A, Miyata H. Muscle fiber population and

279 biochemical properties of whole body muscles in Thoroughbred horses. The Anatomical Record:

280 Advances in Integrative Anatomy and Evolutionary Biology: Advances in Integrative Anatomy and

281 Evolutionary Biology. 2009;292(10):1663-9. doi:10.1002/ar.20961

282
22. Stull CL, Albert WW. Comparison of muscle fiber types from 2-year-old fillies of the belgian, standardbred, thoroughbred, quarter horse and welsh breeds. Journal of Animal Science.

1980;51(2):340-3. doi:10.2527/jas1980.512340x

23. Valberg SJ. Muscle Anatomy, Physiology, and Adaptations to Exercise and Training. In:

Hodgson DR, McKeever KH, McGowan CM, editors. The athletic horse: principles and practice of equine sport medicine. 2nd ed. St. Louis: Elsevier; 2014. pp. 174-201. 
288 24. Franklin SH, Van Erck-Westergren E, Bayly WM. Respiratory responses to exercise in the horse.

289 Equine Veterinary Journal. 2012;44(6):726-32. doi:10.1111/j.2042-3306.2012.00666.x

290 25. Lekeux P, Art T, Hodgson DR. The respiratory system: anatomy, physiology, and adaptations to

291 exercise and training. In: Hodgson DR, McKeever KH, McGowan CM, editors. The athletic horse:

292 principles and practice of equine sport medicine. 2nd ed. St. Louis: Elsevier; 2014. Pp 125-154.

293 26. Hörnicke H, Weber M, Schweiker W. Pulmonary ventilation in Thoroughbred horses at

294 maximum performance. Equine exercise physiology. 1987;2:216-24. 